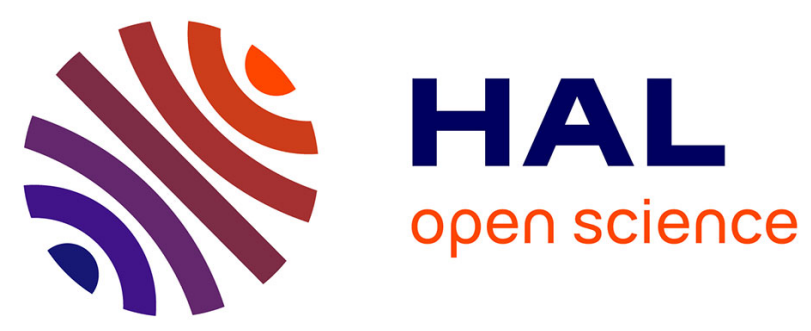

\title{
Short-pulse and high-repetition-rate diode-pumped Yb:CaF2 regenerative amplifier
}

Sandrine Ricaud, Frédéric Druon, Dimitris N. Papadopoulos, Patrice Camy, Jean-Louis Doualan, Richard Moncorgé, Martin Delaigue, Yoann Zaouter, Antoine Courjaud, Patrick Georges, et al.

\section{To cite this version:}

Sandrine Ricaud, Frédéric Druon, Dimitris N. Papadopoulos, Patrice Camy, Jean-Louis Doualan, et al.. Short-pulse and high-repetition-rate diode-pumped Yb:CaF2 regenerative amplifier. Optics Letters, 2010, 35 (14), pp.2415-2417. 10.1364/OL.35.002415 . hal-00533092

\section{HAL Id: hal-00533092 \\ https://hal-iogs.archives-ouvertes.fr/hal-00533092}

Submitted on 8 Nov 2010

HAL is a multi-disciplinary open access archive for the deposit and dissemination of scientific research documents, whether they are published or not. The documents may come from teaching and research institutions in France or abroad, or from public or private research centers.
L'archive ouverte pluridisciplinaire HAL, est destinée au dépôt et à la diffusion de documents scientifiques de niveau recherche, publiés ou non, émanant des établissements d'enseignement et de recherche français ou étrangers, des laboratoires publics ou privés. 


\title{
Short pulse and high repetition rate diode-pumped
}

\section{$\mathrm{Yb}: \mathrm{CaF}_{2}$ regenerative amplifier}

\author{
S. Ricaud ${ }^{1,4}$, F. Druon ${ }^{1}$, D. N. Papadopoulos ${ }^{1,2}$, P. Camy $^{3}$, J. L. Doualan ${ }^{3}$, R. Moncorgé Me $^{3}$ \\ M. Delaigue ${ }^{4}$, Y. Zaouter ${ }^{4}$, A. Courjaud ${ }^{4}$, P. Georges ${ }^{1}$ and E. Mottay ${ }^{4}$ \\ ${ }^{1}$ Laboratoire Charles Fabry de l'Institut d'Optique (LCFIO), UMR 8501CNRS, \\ Université Paris-Sud, RD 128 Campus Polytechnique, 91127 Palaiseau, France \\ ${ }^{2}$ Institut de la Lumière Extrême (ILE), UMS 3501 CNRS, Ecole Polytechnique, \\ ENSTA ParisTech, Institut d'Optique, Université Paris-Sud, Palaiseau, France \\ ${ }^{3}$ Centre de recherche sur les Ions, les Matériaux et la Photonique (CIMAP), \\ UMR 6252 CEA-CNRS-ENSICAEN, Université de Caen, 14050 Caen, France \\ ${ }^{4}$ Amplitude Systèmes, 6 allée du doyen Georges Brus, 33600 Pessac, France \\ Corresponding author: sandrine.ricaud@institutoptique.fr
}

\begin{abstract}
We present a diode-pumped regenerative amplifier based on an $\mathrm{Yb}: \mathrm{CaF}_{2}$ crystal optimized to produce short pulses for various repetition rates ranging from $100 \mathrm{~Hz}$ to $10 \mathrm{kHz}$. The shortest pulse duration generated is 178 -fs, and the corresponding energy is $1.4 \mathrm{~mJ}$ before compression ( $620 \mu \mathrm{J}$ after), at a repetition rate of $500 \mathrm{~Hz}$ for $16 \mathrm{~W}$ of pump power. The bandwidth is $10 \mathrm{~nm}$ centered at $1040 \mathrm{~nm}$. Higher repetition rate regimes have also been explored allowing an optical-optical efficiency up to $10 \%$ at high repetition rate. (C) 2010 Optical Society of America
\end{abstract}

OCIS codes: $140.3280,140.3380,140.3480,140.3615,140.7090$. 
More and more industrial applications require reliable, efficient and compact laser configurations. From this point of view, due to their favorable spectroscopic and thermal properties, diode-pumped systems based on ytterbium-doped crystals are now very popular for the production of high energy and ultra-short laser pulses.

Many research efforts have been devoted to the generation of short and energetic pulses both in oscillator and amplifier setups based on these Ytterbium-doped crystals. Within oscillators, ultra-short pulses (down to 47 fs with Yb:CALGO [1]) or high average powers (80 W) [2] combined with energetic laser pulses (25 $\mu \mathrm{J}$ with $\mathrm{Yb}: \mathrm{YAG}$ in thin disk structures) have been obtained. Nevertheless, for energies above the $\mathrm{mJ}$ range, regenerative amplifiers are required, but a compromise between high average power and short pulse duration is necessary. To overcome the limited available bandwidth, one method consists of combining gain media with slightly shifted but overlapping bandwidths, as in the regenerative thin-disk Yb:KYW amplifier presented in ref. 3 (500 $\mu \mathrm{J}$ sub 200 fs pulses). Investigating new materials is another approach to access broad gain spectra and generate shorter and more energetic pulses.

Recently, a "new-old" [4] laser material demonstrated very promising results for short and energetic pulse generation. Indeed, $\mathrm{Yb}: \mathrm{CaF}_{2}$ offers good thermal properties (thermal conductivity of $9.7 \mathrm{~W} \mathrm{~m}^{-1} \mathrm{~K}^{-1}$ for undoped material [5] and still around $5.0 \mathrm{~W} \mathrm{~m}^{-1} \mathrm{~K}^{-1}$ for 5-at. .$\%$ doping level [6]), together with broad emission and absorption bands due to the particular arrangement of the $\mathrm{Yb}^{3+}$ ions in the structure of $\mathrm{CaF}_{2}$ [4]. Furthermore, $\mathrm{Yb}: \mathrm{CaF}_{2}$ has a long fluorescence lifetime of $2.4 \mathrm{~ms}$ [5], indicating high energy storage capacity, and therefore allowing the generation of energetic pulses at repetition rates in the $100 \mathrm{~Hz}$ range.

So far, these properties have been exploited in the context of diode-pumped systems in an ultrashort oscillator producing sub-100 fs pulses [7] and in a very high energy TW amplifier [8]. This TW system generates $197 \mathrm{~mJ}, 192 \mathrm{fs}$ pulses at low repetition rate $(1 \mathrm{~Hz})$, and with an 
optical-to optical conversion efficiency of $1.4 \%$. Codoped $\mathrm{Yb}^{3+}, \mathrm{Na}^{+}: \mathrm{CaF}_{2}$ has also been used in a cryogenically cooled regenerative amplifier [9]. In this work, pulses at a repetition rate of $1 \mathrm{kHz}$ are generated, with an energy of $3 \mathrm{~mJ}$ before compression (optical-to-optical conversion efficiency of $3.1 \%$ ), and a duration of 195 fs after compression. However, $\mathrm{Na}$ codoping seems to lead to several differences compared to $\mathrm{Yb}: \mathrm{CaF}_{2}$ such as a lower thermal conductivity, a more structured emission spectrum and a longer lifetime.

In this paper we present a room-temperature diode-pumped regenerative amplifier based on a singly doped $\mathrm{Yb}: \mathrm{CaF}_{2}$ single crystal, allowing the generation of $\mathrm{mJ}$ sub-200 fs pulses with a high conversion efficiency. The limitations in terms of pulse duration of $\mathrm{Yb}: \mathrm{CaF}_{2}$ amplifiers versus repetition rate are examined. For that, we investigate the influence of gain shaping in Q-switched and injected regimes, as a function of repetition rate.

The experiment is performed with a 2.6-\% Yb doped 5-mm-long Brewster-cut $\mathrm{CaF}_{2}$ crystal grown by using the Bridgman technique. The experimental setup, and particularly the regenerative amplifier, is illustrated in fig. 1 . The crystal is in a copper mount. To optimize the injection pulse spectrum in terms of bandwidth and maximum gain, the seed pulses are generated by a broadband Yb:CALGO oscillator centered at $1043 \mathrm{~nm}$ with a FWHM bandwidth of $15 \mathrm{~nm}$ (fig. 2) at a repetition rate of $27 \mathrm{MHz}$ [10]. The pulses are stretched to 260 ps with a transmission grating $(1600 \mathrm{l} / \mathrm{mm})$. The regenerative amplifier contains a thinfilm polarizer (TFP) and a BBO Pockels cell (PC) for polarization switching and hence injecting and extracting the oscillator pulses and the amplified pulses, respectively. The amplifier crystal is longitudinally pumped through a dichroic mirror using a $16-\mathrm{W} 200-\mu \mathrm{m}$ (N.A. 0.22)-fiber-coupled laser diode emitting at $980 \mathrm{~nm}$. Thanks to the broad absorption band of the crystal, the emission wavelength of the laser diode does not need any stabilization with Bragg gratings. To optimize the overlap between the laser and the pump beams, the diode is collimated and focused by two $50 \mathrm{~mm}$ focal-length triplets to reduce optical 
aberrations. The cavity is designed in order to obtain diffraction limited laser beam at the output, with a cavity length of about $1.5 \mathrm{~m}$. The Pockels cell is adjusted to act as a quarter wave plate at $45^{\circ}$ in static state, i.e. without high voltage, and as a half wave plate with quarter wave voltage applied to the electrodes. Between the stretcher and the amplifier, a TFP, a Faraday rotator (FR) and a half-wave plate are placed in order to separate input and output beam. Finally, after a beam expander, the chirped pulses are compressed using two transmission gratings $(1600 \mathrm{l} / \mathrm{mm})$, with an overall efficiency of $45 \%$.

$\mathrm{Yb}: \mathrm{CaF}_{2}$ spectral gain depends on the population inversion level - as for all $\mathrm{Yb}$-doped gain media - due to the interplay between reabsorption and stimulated emission. This results, in a maximum gain around $1045 \mathrm{~nm}$ for low inversion rate and around $1035 \mathrm{~nm}$ for high inversion rate. In Q-switched operation, it is possible to balance these two peaks in order to obtain broad spectra. At $100 \mathrm{~Hz}$, for example, a bandwidth of $16 \mathrm{~nm}$ FWHM can be obtained with a "camel" shape transcribing the valley at $1040 \mathrm{~nm}$ observable in the spectral gain profile. In this case the nanosecond pulses have an energy of $1.8 \mathrm{~mJ}$.

In the regenerative amplifier configuration, we also notice spectral shaping effects as a function of the repetition rate due to the relationship between the population inversion and the gain in $\mathrm{Yb}$-doped material. For high repetition rates (lower inversion levels) the spectrum exhibits a red shift. This effect is also observed at fixed repetition rate, as shown in fig. 2 , by slightly changing the extraction time. It is therefore possible to obtain a broad spectrum for repetition rates below $1 \mathrm{kHz}$. Above this value, the pulse duration increases due to the low inversion-induced red-shift as shown in fig. 3. For example, the shortest pulse duration at 10 $\mathrm{kHz}$ is $400 \mathrm{fs}$ with a $7.3 \mathrm{~nm}$-bandwidth spectrum centered at $1045 \mathrm{~nm}$.

Generally, at lower repetition rate the amplified pulses are broader, and the shortest pulses obtained have a spectral bandwidth between 10 and $15 \mathrm{~nm}$ FWHM. The short pulse regime is typically accessible between few $\mathrm{Hz}$ up to the $\mathrm{kHz}$, with the shortest pulses obtained at 500 
$\mathrm{Hz}$ repetition rate. The pulse duration in this case, measured both by frequency-resolved optical gating (SHG-FROG) and autocorrelation is $178 \mathrm{fs}$. The input spectrum (centered at $1043 \mathrm{~nm}$ ) is slightly blue shifted to $1040 \mathrm{~nm}$, and the amplified pulse spectrum has a bandwidth of $10 \mathrm{~nm}$ (fig. 4). The energies before and after compression are respectively 1.4 $\mathrm{mJ}$ and $620 \mu \mathrm{J}$ with optical-to-optical efficiency of $4.4 \%$ (before compression), which leads, taking into account a pump absorption of $62 \%$, to a laser/absorbed-pump-power efficiency of 7\%. As shown in fig. 1 , the beam profile exhibits a Gaussian shape, with $\mathrm{M}^{2}<1.1$ in both vertical and horizontal directions.

As mentioned before and shown in fig. 2, broader spectra are also accessible in this low repetition rate regime. Nevertheless, these broadband spectra do not correspond to the shortest pulses since we were unable to compress them to the transform-limit. For example, at $500 \mathrm{~Hz}$ repetition rate, for a 14-nm-broad spectrum the compressed pulse durations is 200 fs. As confirmed by our FROG measurements, this incomplete compression is due to remaining high order phase distortions.

In figure 5 the output energy of the amplifier is ploted against the repetition rate. The maximum energy plateau occurs at a repetition rate below $300 \mathrm{~Hz}$ (fig. 5) which is in agreement with the lifetime of $2.4 \mathrm{~ms}$ of $\mathrm{Yb}: \mathrm{CaF}_{2}$. The maximum pulse energy is $1.6 \mathrm{~mJ} / 700$ $\mu \mathrm{J}$ (uncompressed/compressed) corresponding to 130 roundtrips.

At high repetition rate, typically $10 \mathrm{kHz}$, the output energy is strongly reduced while an average power as high as $1.4 \mathrm{~W}$ before compression ( $0.6 \mathrm{~W}$ after) is obtained. This corresponds to an optical-optical efficiency of $9 \%$ (before compression) due to the absorption increase to $72 \%$, and a laser/absorbed-pump-power efficiency of $12 \%$. For comparison, in cw regime we have obtained up to $13 \%$ of optical-to-optical efficiency.

In conclusion, we have demonstrated a diode-pumped room-temperature regenerative $\mathrm{Yb}: \mathrm{CaF}_{2}$ amplifier operating at high repetition rate. Seeded with pulses from an $\mathrm{Yb}$ : CALGO 
oscillator, this amplifier delivers short pulses $(\approx 180 \mathrm{fs})$ at up to $1 \mathrm{kHz}$ repetition rate. The maximum extracted energy is $1.6 \mathrm{~mJ} / 0.7 \mathrm{~mJ}$ (before / after compression). The highest average power is $1.4 \mathrm{~W} / 0.6 \mathrm{~W}$ (before / after compression) corresponding to an optical efficiency around $10 \%$. The bandwidth of the output pulses shows potential for sub-100 fs pulses if high order phase distortion is controlled. Furthermore considering the good thermal properties of the crystal, one can expect to obtain higher average power at high repetition rates thanks to higher pumping, moreover, using a cryogenically cooled crystal should really scale up the average power of the amplifier. 
[1] Y. Zaouter, J. Didierjean, F. Balembois, G. Lucas Leclin, F. Druon, P. Georges, J. Petit, P. Goldner, and B. Viana, "47-fs diode-pumped $\mathrm{Yb}^{3+}: \mathrm{CaGdAlO}_{4}$ laser," Opt. Lett. 31(1), 119-121 (2006).

[2] J. Neuhaus, D. Bauer, J. Zhang, A. Killi, J. Kleinbauer, M. Kumkar, S. Weiler, M. Guina, D. H. Sutter, and T. Dekorsy, "Subpicosecond thin-disk laser oscillator with pulse energies of up to 25.9 microjoules by use of an active multipass geometry," Opt. Express 16(25), 20530-20539 (2008).

[3] U. Buenting, H. Sayinc, D. Wandt, U. Morgner, and D. Kracht, "Regenerative thin disk amplifier with combined gain spectra producing $500 \mu \mathrm{J}$ sub 200 fs pulses," Opt. Express 17(10), 8046-8050 (2009).

[4] M. Siebold, S. Bock, U. Schramm, B. Xu, J. L. Doualan, P. Camy, and R. Moncorgé, "Yb:CaF $\mathrm{Ca}_{2}$ - a new old laser crystal," Appl. Phys. B 97(2), 327-338 (2009).

[5] P. Camy, J.L. Doualan, A. Benayad, M. von Edlinger, V. Ménard, and R. Moncorgé, "Comparative spectroscopic and laser properties of $\mathrm{Yb}^{3+}$-doped $\mathrm{CaF}_{2}, \mathrm{SrF}_{2}$ and $\mathrm{BaF}_{2}$ single crystals," Appl. Phys. B 89(4), 539-542 (2007).

[6] J. Petit, P. Goldner, and B. Viana, "Laser emission with low quantum defect in Yb:CaGdAlO

[7] F. Friebel, F. Druon, J. Boudeile, D. N. Papadopoulos, M. Hanna, P. Georges, P. Camy, J. L. Doualan, A. Benayad, R. Moncorgé, C. Cassagne, and G. Boudebs, "Diodepumped 99 fs Yb:CaF 2 oscillator," Opt. Lett. 34(9), 1474-1476 (2009).

[8] M. Siebold, M. Hornung, R. Boedefeld, S. Podleska, S. Klingebiel, C. Wandt, F. Krausz, S. Karsch, R. Uecker, A. Jochmann, J. Hein, and M. C. Kaluza, "Terawatt diodepumped Yb:CaF 2 laser," Opt. Lett. 33(23), 2770-2772 (2008). 
[9] A. Pugžlys, G. Andriukaitis, A. Baltuška, L. Su, J. Xu, H. Li, R. Li, W. J. Lai, P. B.

Phua, A. Marcinkevicius, M. E. Fermann, L. Giniunas, R. Danielius, and S. Ališauskas, "Multi-mJ, 200-fs, cw-pumped, cryogenically cooled, Yb,Na:CaF 2 amplifier," Opt. Lett. 34(13), 2075-2077 (2009).

[10] D. N. Papadopoulos, F. Druon, J. Boudeile, I. Martial, M. Hanna, P. Georges, P. O. Petit, P. Goldner, and B. Viana, "Low-repetition-rate femtosecond operation in extendedcavity mode-locked Yb:CALGO laser," Opt. Lett. 34(2), 196-198 (2009). 
Fig. 1. Experimental setup: M1, M2, M3 and M4, plane HR mirrors; FR, Faraday Rotator; PC, Pockels Cell. M1-R300: 600mm; R300-Crystal: 170mm; Crystal-R300: 165mm; R300M2: $500 \mathrm{~mm}$. Inset, profile of the $1.4 \mathrm{~mJ} 500 \mathrm{~Hz}$ output beam.

Fig. 2. Evolution of the spectrum of the amplified pulse at $500 \mathrm{~Hz}$ repetition rate for different time of extraction: $1.35 \mu \mathrm{s}, 300 \mu \mathrm{J}$ (red curve), $1.7 \mu \mathrm{s}, 620 \mu \mathrm{J}$ (blue curve), $2.2 \mu \mathrm{s}, 580 \mu \mathrm{J}$ (green curve). Short dash curve corresponds to the oscillator spectrum.

Fig. 3. Evolution of pulse duration after compression vs repetition rate.

Fig. 4. Recompressed pulse measurement with SHG FROG for output energy of $620 \mu \mathrm{J}$ at a repetition rate of $500 \mathrm{~Hz}$.

Fig. 5. Evolution of output pulse energy and average power after compression vs repetition rate. 


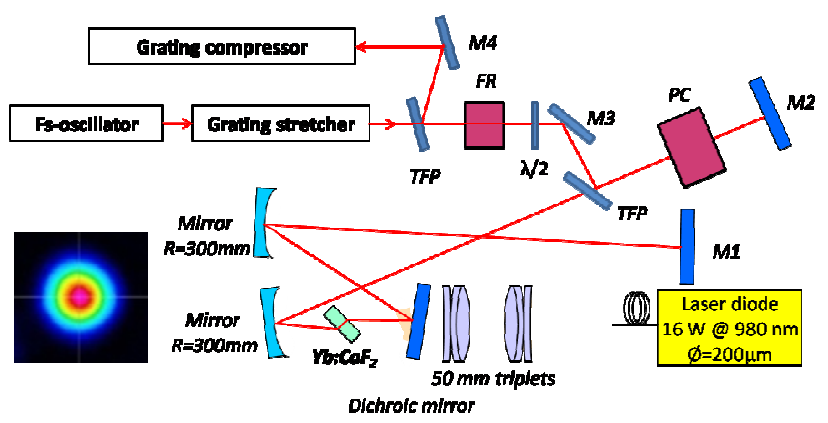




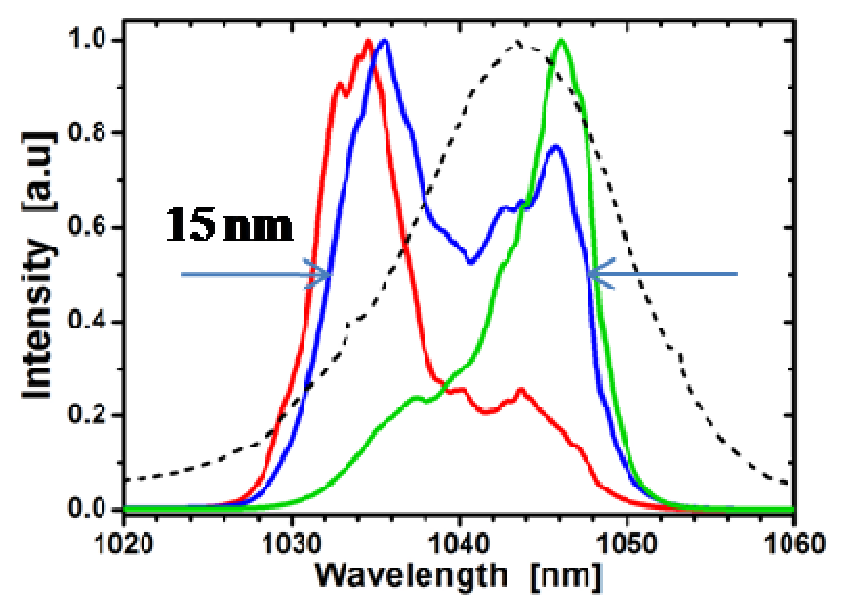




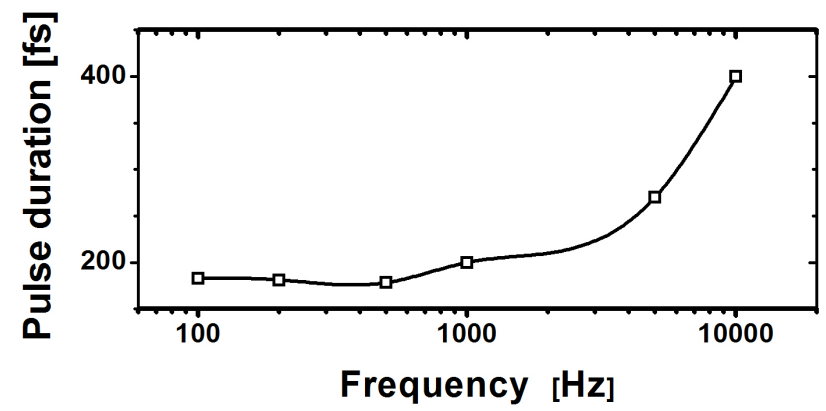



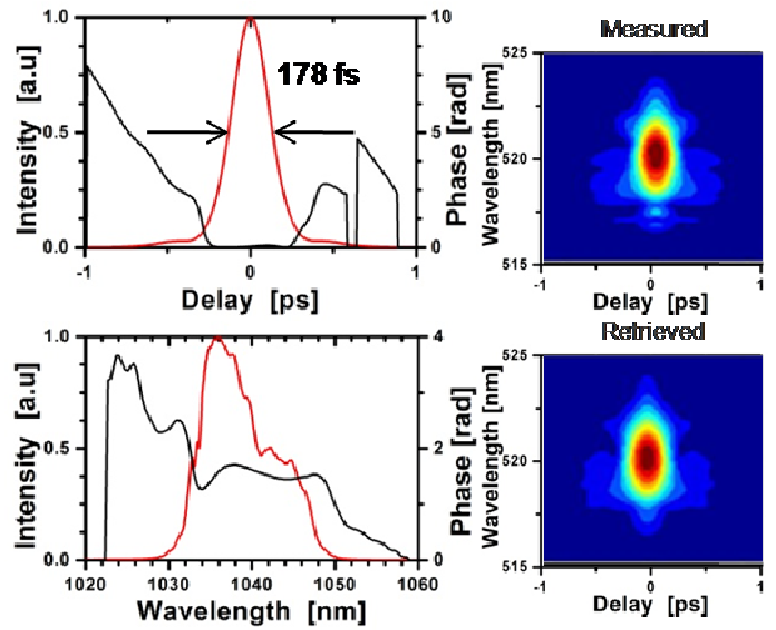


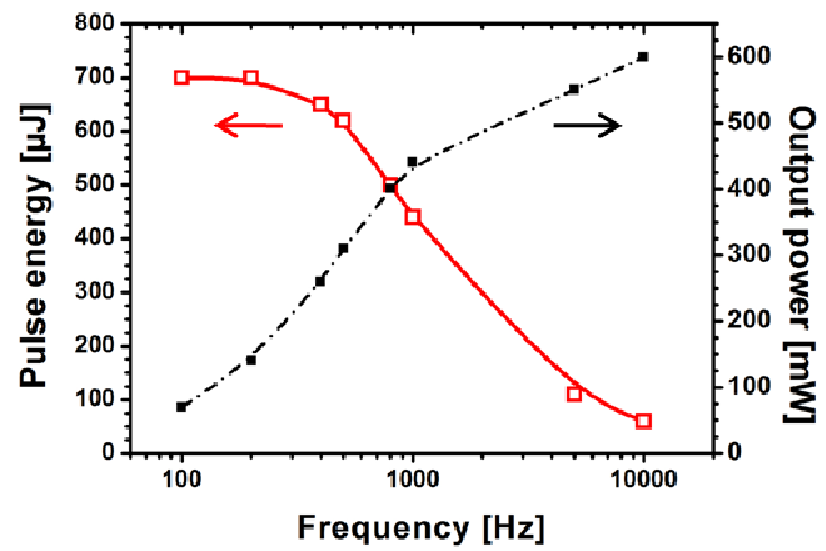

